\title{
Reflexive Competence in the Structure of Future Music Teachers' Training: the Modern Vector of Research
}

\author{
Luis Socrates Cueva Davila, Natalia Shetelia
}

\begin{abstract}
The article presents an analytical and reflexive analysis of the problem of music teachers' training in the context of educational changes. The peculiarities and specifics of Musical Arts specialists' training are outlined; priorities in the creation of an educational environment in modern higher education institutions are defined as compared to the near and far-abroad countries. Factors contributing to music teachers' training increased efficiency and popularity are substantiated. It is established that such a resource is the formation of reflexive competence. The means of forming reflexive competence in future music teachers are visualization, testing (paper- and computerbased), electronic textbooks, videos, multimedia, and stages within which reflexive competence is formed, where the priority is given to a reflective workshop.
\end{abstract}

Keywords: reflexive competence, future music teachers' training, formation means and stage, reflective workshop.

\section{Introduction}

Higher education orientation towards the values of the student's personal development necessitates changes in requirements for teachers' training, their professionalization as the process of the formation and development of professional consciousness and self-consciousness, and the acquisition of key competencies necessary to successfully perform professional functions (V. Bezpalko, V. Hordienko, O. Derkach, N. Kuzmina, A. Markova, L. Masol, 2004; O. Padalka, O. Pekhota, O. Rudnytska, etc.).

One of the main requirements for higher education is professionals' training forming in them the sense of their purpose and role in society. According to the ancient pedagogical truth, the school will be what the teacher will be. Accordingly, pedagogical process success will be largely determined by the teacher's competence - «functional ability to adequately perform certain activities as well as to have sufficient knowledge and skills» (Masol, 2004; Shcholokova, 2011). 


\section{Statement of basic materials}

In scientific research (O. Babchenko, I. Bohdanova, V. Hasniuk, N. Kuzmina, A. Lynenko, V. Medushevskyi, O. Rostovskyi, etc.), various aspects of teachers' training are discussed. The leading ones are traditional and modern. The former focuses on the training of a musician as a specialist (i.e. a model of training a professional musician), which is associated with the traditional concept of music education at school - to teach music, to teach to play it. The latter, a modern aspect, assesses the need for good music performance but it is not central to the teacher's professionalism. This model ensures the teacher's musical culture, in which their training as performers plays a great role (Kremeshna, 2015; Shcholokova, 2011).

Music education, as well as music teachers' training, originated in the ancient world, in Greece, where music was a compulsory subject for young people. It was a kind of evidence for public concern for the educational and socio-political importance of music education. This tradition has survived to this day in European countries.

In most countries of South and Latin America, such professionals' training is carried out in conservatories or music faculties, which differ mainly in the organization of the educational process rather than programs and teaching methods.

In Japan, the process of creating modern music institutes began earlier than in other countries in Asia and Africa (early 19th century). L. Masol (2004), the well-known American musician and educator, was invited by the Japanese government to organize music education (1879). His work and experience in school music training is a resource that has become traditional in Japan («Mason’s Songs»). Musical Arts specialists' training is carried out in higher education institutions such as music universities (formerly the academic school of music), music faculties, and colleges. Great importance in the process of such training is given to the Suzuki method which is based on the development of auditory skills through violin playing.

The centers of music education in India are the Academy of Music, Dance and Drama, music colleges, and music faculties that operate at universities. The best Indian music professionals (playing the sitar and wine, the art of raga, improvisation, etc.) are involved in music teachers' training. Training programs cover a variety of Indian music, as well as reflect its connection with other Arts (dance and drama).

Significant reforms in music education (at all levels) have taken place in Arab countries. In 1959, in Egypt, in particular, in Cairo, conservatories with theoretical and performance faculties began their activities. This is the Academy of Arabic Music, the Institute of Arabic Music studying traditional 
music and playing national instruments. Personnel's training for the development of music education in schools is carried out in special institutes training music teachers - the Academy of Fine Arts with a department of music (Baghdad), three branches of the National Institute of Music (research, teaching, and folklore in Algeria). It should be noted that specialists from other countries, including Ukraine, are invited to provide such training.

The experience of training music teachers in Israel is also of interest. Highly qualified professionals - music teachers, performers, composers, and choreographers - who are highly respectable internationally, with proven performance and pedagogical qualifications are trained there. The Faculty of Composition, Conducting, and Music Pedagogy trains school music teachers, music professionals for preschools, and high-level musicologists.

Training is carried out according to different methods and leading systems of music teaching (D. Kabalevskyi, Z. Kodai, etc.). In addition to classes in rhythmics, psychology, methodology, voice training, students undertake an internship under the guidance of teachers at schools and preschools. It is mandatory to attend classes in the main instrument (electively) and in the guitar as an additional instrument.

As a part of future music teachers' professional and competence development, a graduate department organizes master classes, lectures, meetings and the concerts of leading pianists from Israel and abroad. Course study can be varied at students' discretion and with the consent of the faculty administration to implement various joint projects and individual programs. Students who have completed four years of study and successfully passed all exams according to the plan of the Department of Music Teachers' Training for Schools and Preschools receive a bachelor's degree in music pedagogy (B.Ed.Mus.) as well as recommendations and assistance in finding jobs across the country.

In higher education institutions in Russia, Europe, the USA, and Australia, future music teachers' training is carried out taking into account ISO 9000 standard (Cueva, 2014). It is noteworthy that Ukraine has also set to implement and realize this standard. The main determinants of such training content are the following:

- timely provision of technological assistance, taking into account the available reserves and restrictions;

- material support (improvement of musical and technical means);

- resources that promote innovative improvement (computer programs, improvisation, modeling);

- future resource requirements planning. 
The modern context of music teachers' training should address the organization of students' activities in those types, forms, and methods that represent a new training strategy - the formation of reflexivity.

It should be borne in mind that music teachers' professional activity has its specifics, which are to create full-fledged conditions for musical and aesthetic training and children's development in classroom, out-of-class, and out-of-school activities.

In the conditions of information educational space, the requirements for future music teachers' training aimed at the facilitation of their professional and personal becoming and development are getting stronger. An important result of such development is the readiness to comprehensively consider complex teaching activity objects as holistic phenomena, to align the goals of teaching with the student's personality development and the trends in school activities with regard to paradigmatic changes in teaching approaches and methods. This level of readiness to perform all the functions of professional and pedagogical reflection is possible to achieve if a future teacher understands the value of the reflective position and seeks to master the ability to implement it.

Instead, teachers' experience shows that the level of their personal and professional self-development (necessary to achieve a new quality of education) does not fully meet the requirements of school and society. In addition, not every teacher is ready to independently carry out their professional self-development, reflectively analyze performed activities, and be aware of their potential, etc.

In this connection, the problem of forming the reflexive competence in the future teacher in the professional training process is becoming extremely important.

By this concept scientists understand the ability to manifest in real practice the willingness to realize teachers' potential (knowledge, skills, experience, and personal qualities) for successful creative (productive) activities in professional and social spheres, to understand the social significance and personal responsibility for this activity outcomes and its continuous improvement.

We consider reflexive competence as a professional quality of personality, which allows carrying out reflective processes effectively and adequately, reflexive ability realization, contribution to development and self-development, and the promotion of the creative approach in professional activities. It leads to the achievement of its maximum efficiency and effectiveness. So, it is possible to identify a direct correlation between reflexive competence and the achievement of the highest results in the future teacher's personal and professional development. 
Acmeology studies the highest path to pedagogical professionalism. Acmeology, in O. Anisimov's terms, discloses the concept of reflexive competence from the standpoint of metacompetence, through the knowledge and mastery of the reflection mechanism. It contributes to the adequate development of all other professional competence types. Reflection development plays a crucial role in the educational space of any complexity level, at any stage of teachers' education and self-education under the following conditions:

1) not only the appropriation of the world of objects and ideas but also their transformation, the creation of new ones;

2) awareness and perception of tasks at all implementation stages and the individual's desire to set them independently as needed;

3) identification, the rationale for choosing, and the use of the individual self's resources; ability to make moral choices in conflict situations;

4) the need for the reflection capability as a condition for conscious regulation of one's behavior and activities in accordance with desires and goals, on the one hand, and the awareness of the limits of «one's freedom»on the other;

5) the desire to proactively, critically, and innovatively reflect on activity results and relationships in the process of forming a proactive professional attitude;

6) the focus on self-development;

7) the presence of internal independence from the «outside world» not in the sense of ignoring it but in terms of the stability of views, beliefs, purposes, their correction and change in accordance with situation requirements;

8) the emergence of creative potential, uniqueness, and individuality, etc. (Sidorov, ).

The most effective reflexive competence development is achieved by using reflexive teaching methods and creating acmeological conditions, namely, the presence of a common problem field, its correlation with participants' professional experience, and the removal of interpersonal barriers in organizing collective mental activities and reflective environment. In addition, participants' personal involvement in reflective workshops in the thinking process and activities increasing learning effectiveness is required.

As a result, in addition to increasing subject professional competence expressed in the amount of specific professional activity knowledge, the development of problem-solving skills, the ability to work together and 
overcome conflict situations, enrich professional and personal experience factors contributing to high performance - are realized.

Therefore, the future specialist's reflection should be focused on the self-awareness and identity formation of the subject in their perception of themselves, when there is a differentiation of internal cues and ways to distinguish between «self» and «non-self«; when the subject treats themselves as an object of management, and reflection becomes the main means of selfdevelopment, a condition and way of personal and professional growth. Therefore, reflection internal mechanisms as a component of the future specialist's professional activities can be conditionally classified according to the following characteristics:

a) analysis of one's consciousness and activities (self-reflection);

b) understanding interpersonal communication and finding out how others know, understand, and evaluate a «reflective» personality (interpersonal and intellectual) (Kremeshna, 2015; Marusynets, 2018).

In this context, reflexive competence should be «intertwined» in the context of the future music teacher's professional becoming and development.

Transforming into the future music teacher's professional training, reflexive competence is manifested in its following types: cooperative reflection (knowledge of collective interaction role functions and positional organization); communicative (ideas about another person's inner world, psychological determinants of their activities and relationships); personal (ideas about one's actions and relationships, self-perception as an individual); intellectual (knowledge of objects and ways of interacting with them, the ability to introspectively review and track the progress of one's intellectual and professional activities).

Thus, reflexive competence is a complex, personal formation that integrates such reflection types as cooperative, communicative, personal, and cognitive. In a holistic perception, these types of reflexive competence determine the level of its formation in educational activity subjects.

Under these conditions, reflection will contribute to the fact that the activity of the future specialist's personality will acquire a purposeful, subject-oriented nature. This will help a student to better understand and be aware of their professional activities

The means of forming the reflexive competence of future music teachers are visualization, testing (paper-and computer-based), electronic textbooks, videos, and multimedia.

We will describe the stages within which the formation of reflexive competence is carried out (motivational and purposeful, organizational and activity, reflexive evaluation). 
The motivational and purposeful stage implies students' familiarization with the profession of a music teacher, its advantages, opportunities for the development of reflection and reflexive competence by means of music, musical perception and musical thinking, and the ability to assess one's position in the chosen activity. The main methods of its realization are a reflective conversation, a reflective dialogue, a portfolio, and pedagogical problem solving.

The organizational and activity stage is aimed at the formation in students of knowledge, skills and abilities necessary for the music teacher's professional activity from the standpoint of reflexive competence, methods and means of its implementation; self-attitude as a future teacher, the ability to adequately assess oneself and the pedagogical situation from the standpoint of a specialist. The methods chosen are role and didactic games, the case method, reflective dialogues, and reflective conversations. They boost the development of the ability to put forward and solve problems taking into account the variability of thought in mastering the key special competences of the studied phenomenon; ensure the formation of a reflexive position and goal-setting ( $\mathrm{I} \mathrm{am}$ a teacher in mastering subject competences», «I am a teacher through the eyes of students«); help to stand one's ground in teaching music to students using innovative technologies; attending and conducting lessons/classes in secondary school, solving pedagogical problems while studying and analyzing musical works.

At the reflexive evaluation stage, preference is given to a generalizing reflective workshop consisting of a reflexive training, project exercises, tasks for modeling students' personal learning progress.

The formation of future music teachers' reflexive competence resulting from the implementation of our model, is checked through the monitoring of:

a) levels of reflexive competence formation (high, average, and low);

b) diagnostics of reflexive competence formation qualities

Given the importance of higher education tasks in the future specialist's professional development, there arises a question about the organization of methodological (procedural) conditions for its provision. Such conditions imply the circumstances which the teacher's relationships with students depend on determining interaction and a solution of integral tasks and contributing to the satisfaction of pedagogical phenomenon actors or participants' requests and interest (Biliakovska; Cueva Davila, 2014).

In scientific studies, researchers define pedagogical conditions as a category that covers a system of certain forms, methods, material conditions, and real situations created to achieve a specific pedagogical goal (Masol, 2004); as circumstances of the education process with allow the achievement of a certain 
pedagogical goal (Shcholokova, 2011) and contribute to the transformation (modeling) of possible personality traits into real ones (Kremeshna, 2015; Sidorov, ).

Pedagogical conditions are a set of socio-pedagogical and didactic circumstances that affect the learning process and manage it enabling its rationality, the richness of content through the use of effective teaching forms, methods, and techniques (Marusynets, 2018; Cueva Davila, 2014). We consider pedagogical conditions as a reflection of the structure of future music teachers' readiness to work with primary, secondary, and high school students. The main pedagogical conditions that will contribute to the formation of reflexive competence, as we identified at the search stage of the study, are the following:

- future music teachers' motivation for a professionally oriented reflexive position as a priority in personal and professional training;

- creation of educational, developmental, and reflective environment focused on the formation of reflexive competence components;

- orientation of future music teachers to reflexive competence selfimprovement.

The described set of pedagogical conditions covers both internal conditions provided by the subject of activity and defined by students' personal attributes (acquired life and art experience, the development of memory, attention, thinking, and other mental processes and phenomena), the formation of their professional qualities (associative imagination, artistic needs, tastes, etc.) and external conditions, under which future professionals' training is carried out.

Internal conditions determine the student's readiness for professional activity, the focus on self-knowledge and the understanding of other subjects of educational interaction; unlocking of professional capabilities in Musical Arts; self-discipline and an exacting attitude towards other subjects (classmates, teachers, and parents); assessment and selfassessment of ambition level results (special and general competences); formation of a reflexive position in educational and professional activities.

The latter is expressed in the fact that, for a student, this process is a special management object, and the individual is the subject of this management. That is, a student can act as an independent person only to the extent to which their self-reflection and reflection mechanisms are formed in terms of their activity management (Marusynets, 2018). Accordingly, the external learning conditions depend on the educational institution's environment where the process of future specialists' professional development takes place. M. Marusynets (2018) argues that in the course of educational activities, there should be created conditions that encourage 
students to reflect on their experience, i.e. conditions that enhance the reflection of educational activities and the individual in general. Since educational activity is an activity of a self-change, it is conditioned by :

a) mechanisms of self-changes;

b) systematic (purposeful) formation of reflexive processes (including competences) essential for the self-development of the subject (Marusynets, 2013).

Therefore, the future music teacher focused on the development of reflexive competence should be characterized by the following:

1) the ability to analyze and adequately assess their professional activities and learn colleagues' constructive experience based on thorough theoretical and practical training;

2) the ability to foresee and determine the conditions and means of improving their professional activities;

3) the ability to adjust professional activity and its scientific and methodological support in accordance with social transformations and changing conditions of the present day;

4) the awareness of modern trends in the development of psychological and pedagogical science and the innovative technological means of professional activity, etc.

Given the above, we claim reflexive competence formation to be possible under the condition of a specially created reflective and development environment in higher education institutions.

Let's outline the semantic field of the given concept. In scientific psychological and pedagogical studies, it is considered as a system of conditions for personal development opening up for the specialist's personality the opportunities of self-enquiry and the self-correction of professional resources, the main function of which is to promote the need for reflection - the basic self-development mechanism. Its essential characteristic is dialogueness, which ensures the partnership of interacting subjects' psychological positions.

Cooperation and cooperative creative activities in the innovation process involve the rejection of mentoring, dictation, and contribute to the establishment of a different relationship type: collective search for, the analysis and self-analysis of results. Cooperation in this case does not mean a departure from independence. It's about something else - the rejection of the position that your opinion, your approach are the only correct options. The advantages of the development environment are:

- the intuition of development cooperative creative activities, which provides non-destructive means of self- and mutual development. It means that in solving any task, all participants, regardless of the initial professional 
competence level, are subjects of mutual creation in fundamentally excessive, innovative, and open interaction not only with each other but also with different socio-cultural contexts;

- subjective parity achieved through the recognition of the uniqueness and creative self-worth of each of educational interaction participants;

- self-identification polylogueness ensuring the conscious selfactualization and effective self-realization of each individual, taking into account not only the zone of proximal development but also other educational interaction participants;

- the transfer of the received reflexive experience to the professional sphere;

- leveling of status barriers, which allows going beyond the formal lecture material presentation and provides an opportunity to generate new, innovative ideas without any fear of making a mistake;

-shared interests as a basis for the in-depth understanding of each other's ideas, the development of the ability to accumulate not only one's own experience, but also the achievements of the group as a whole;

- systematic activation and development of different reflexive competence types and kinds.

We will describe the essence of the learning environment in the context of the formation of reflexive competence structural components:

- axiological - the formation of motivation in future music teachers for reflection as a necessary condition of future professional activity effectiveness; students' involvement in various types of musical and pedagogical activities, their awareness of professional opportunities and abilities, moral qualities, and psychological attributes that meet professional requirements; the need for continuous improvement of professional qualities underlying the effectiveness of pedagogic work;

- cognitive and operational - mastering the system of knowledge about students' music and aesthetic education; acquisition of knowledge in psychological and pedagogical disciplines about the peculiarities of primary and secondary school students' educational activities; knowledge about psychological and physiological new formations in students, the sensitive periods of music education and music in general; awareness of the essence of reflection and reflective activity, the development of competencies that make up the content of future specialists' professional training; solving pedagogical problems that arise while working with students when they undertake different pedagogical internship types. For instance, the first attempts to give specific answers to the questions: «What am I doing?», «How will I do it?» 
- emotional and evaluating - the application of acquired knowledge and skills in the practical learning of professional activity basics by students; the consolidation of the acquired reflexive position; reflection and selfreflection, self-assessment and evaluation of one's own actions: «Why do I do it?» «How do I achieve good results?» (for example, to explain the nature of the artistic image of a piece of music), «Is a type of the deep amplitude of a piece of music defined correctly? Why should it be done this way?» etc. Students become aware of professional activity purpose and objectives, they get motivated to achieve them.

- reflexive and corrective - making independent decisions in musicpedagogical activities, which is carried out based on a sufficiently formed level of reflexive competence; development of professional and personal qualities in educational interaction; self-development, self-improvement and self-correction of professional ambition levels in the formation of reflexive competence. The realization of the outlined component is carried out through a reflective practical course «Formation of the future music teacher's reflexive competence» aimed at their self-knowledge and selfimprovement in the process of mastering professional and special competences. The course includes a reflective workshop, project exercises, and assignments for modeling students' personal learning achievements.

The reflective workshop is considered through a specially organized educational and developmental activity, in the process of which the subject acquires knowledge about themselves (as a person and as a professional) through a feedback mechanism. The main attention is paid to the practical implementation of the educational material, in which the simulation of specially created situations is carried out. In such a way, students have the opportunity to consolidate the acquired knowledge, to form relevant skills and abilities, to change the attitude to the chosen profession and its significance as well as to the means by which professional development is carried out. That is, the reflective workshop is a kind of a bridge between theory and practice, which encourages everyone to take concrete actions, provided that moderators (teachers) apply (not passively imitate) scientific knowledge to the requirements of the group encouraging students in such a way to reflect, and self-evaluate their work. Through such self-assessment, students learn the methods of their work classification, decision making about dos and don'ts, when it can be assumed that the goal has been achieved, and what attitudes will be useful in the future (Marusynets, 2013; Cueva Davila, 2014).

The success of the workshop depends on both a moderator and the selection of tasks, the advantage of which is the method of modeling 
personal learning achievements with a projection for future professional activities. Here is the procedure for conducting a reflexive workshop.

1. The reflective workshop «Who I am» developed on the basis of students studying pedagogy, psychology and methods of music education, with the actualization of axiological component formation.

Purpose: formation of motivation types, provoking interest in choosing a profession.

Exercise 1. «Actualization of self-motivations»

Participants are invited to make three statements about their goal realization and the means to achieve it (task-performance time is up to 10 minutes for each series). Series 1. «I never ...»; Series 2. «I want but probably I can't ....;

Series 3. «If I really want, then ...»

Exercise 2. «Agreement».

Each member of the group makes an agreement with themselves and answers the questions: 1. «What do I want to change in myself while studying at university?» 2. «How will I do it?» 3. «What will I get then?»

The agreement should emphasize those behavior patterns that need to be changed, indicate strengths and weaknesses; write down a commitment to be honest with oneself; to state possible changes in oneself, one's communication style, behavior, the circle of acquaintances, entertainments, relations with relatives, and friends; outline specific goals and ways to achieve them. Written agreements are folded into an envelope and handed over to a moderator.

Tasks for discussion:

1. What is my problem? What do I dislike about myself and my life? What worries me?

2. What is the cause of this problem? (Who or what should be blamed for it?)

3. To model the possibilities of solving this problem (which of them depend on $\mathrm{me})$ ?

4. What decision do I make?

Exercise 3. «Projection of self-image.

Workshop participants make two short descriptions on a separate sheet of paper. The first one is a description of how a participant sees themselves, their «I-conception» essays). The second one is how other members of the group see the participant. Descriptions must be thorough and true. The descriptions «How I see myself» are put in a separate box. Each self-description is read aloud, and group members try to guess who it belongs to. The authors then name themselves and read their second 
Trends and Prospects of the Education System and Educators' Professional ...

description (how the participant is treated by others) receiving feedback from the group members.

\section{Conclusions}

Thus, successful training and reflexive competence formation in future music teachers are possible if both internal and external circumstances are fulfilled in the conditions of educational-development and reflective environment in higher pedagogical educational institutions.

\section{References}

Biliakovska, O.O. Teacher's professional competence as a component of effective teaching activities. http://lib.mdpu.org.ua/nvsp/BAK7/7/37.pdf.

Hasniuk, V.V. (2014). Pedagogical potential of Ukrainian and Hungarian artistic traditions and principles of ensuring their interaction in music lessons. Scientific Journal of National Pedagogical Dragomanov University. Series 14. Theory and methodology of arts education. Kyiv: NPU, 16 (21), 1. 150-155.

Dakhin, A. N. Modeling in pedagogy: an attempt to comprehend. http://lib.mdpu.org.ua/nvsp/BAK7/7/37.pdf

Kremeshna, T.I. (2015). Organization of a reflective environment in the process of future music teachers' professional training. Collection of Scientific Papers of Uman State Pedagogical University. Uman: PE Zhovtyi O.O, 2(2). 165-170.

Marusynets, M.M. (2018). Formation of professional reflection in master's degree students: an empirical aspect of research. Scientific Journal of National Pedagogical Dragomanov University. Series 5. Pedagogical Sciences: realities and prospects. K. Publishing house named after M.P. Dragomanov. 64. 145-151

Marusynets, M.M. (2013). Reflexive training as a means of forming the professional abilities of a teacher. Actual problems of psychology: coll. of scientific works of G.S. Kostiuk. Institute of Psychology of the National Academy of Pedagogical Sciences of Ukraine. Kyiv: «Sribna Khvylia», 4(9). 178 -190.

Masol, L.M. (2004). The concept of general art education. Art and education, 1. 2-5.

Sidorov, S.V. Reflexive competence of the teacher and innovator. The site of the teacher and researcher. http://si-sv.com/publ/2-1-0-60].

Shcholokova, O.P. (2011). Scientific Journal of National Pedagogical Dragomanov University. Series 14. Theory and methodology of arts education. 11. 5-19. http://nbuv.gov.ua/UJRN/Nchnpu_014_2011_11_6

Cueva Davila, L. S. (2014). Reflexive competence in the sphere of professional training teachers. Austria, Vitnna, 5/6.120-125.

Rohlfs, E. Musicalische Bildung und Ausbildung. Musik-Almanach 1999/2000: Daten und Fakten zum Musikleben in Deutscbland. Kassel: Barenrelter. 3-21. 